\title{
The City Performance Tool-How Cities Use LCM Based Decision Support
}

\author{
Jens-Christian Holst, Katrin Müller, Florian-Ansgar Jäger \\ and Klaus Heidinger
}

\begin{abstract}
This paper presents the City Performance Tool (CyPT) approach, a LCA-based methodology for sustainable infrastructure decision support. The work presents an outside-in view about the methodology, details about the underlying LCA models and its implementation into a tool. The results for three different cities will be presented and a general conclusion for the use of LCM-based decision support from a business perspective will be given.
\end{abstract}

\section{Introduction}

All over the world, cities are shaped by profound forces: their population, their technologies and their infrastructures. Even today, these forces collide and urbanization and climate change will spur dramatic changes in metropolitan areas. Cities need to pave the way for constant evolution: digital technologies are becoming increasingly important and urban infrastructures and buildings require a more efficient and sustainable setup.

These changing environments set free a swarm of urban challenges. Developed cities for instance need to focus on cutting carbon emissions, improving efficiency in infrastructure and buildings, stimulating a market shift towards cleaner vehicles and more efficient and environmentally friendly public transportation. At the same time, infrastructure quality in many advanced economies is deteriorating. Looking forward to 2030 , more than $\$ 50$ trillion will need to be invested in infrastructure globally to keep up with GDP and population growth [1].

Cities in emerging markets on the other hand face issues such as power outages and inadequate public transport and roads, which brake on growth and development. Infrastructures cannot be built fast enough to keep pace with economic and

J.-C. Holst $(\bowtie) \cdot$ K. Müller · F.-A. Jäger

Siemens AG, Corporate Technology, 13629 Berlin, Germany

e-mail: jens-christian.holst@siemens.com

K. Heidinger

Siemens AG Austria, Siemensstrasse 90, 1210 Vienna, Austria

(C) The Author(s) 2018

E. Benetto et al. (eds.), Designing Sustainable Technologies,

Products and Policies, https://doi.org/10.1007/978-3-319-66981-6_51 

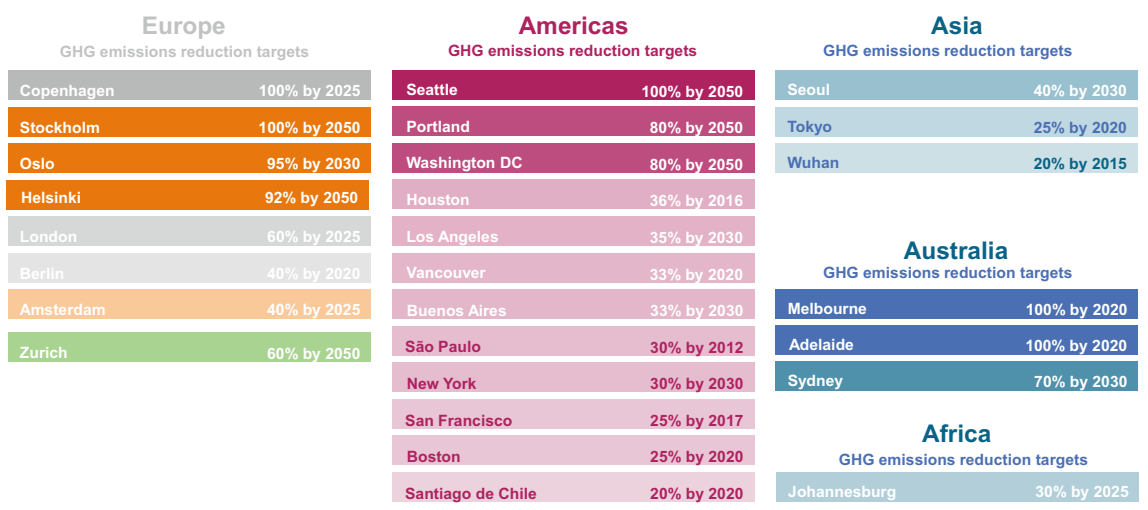

Fig. 1 Environmental reduction targets of different cities worldwide

urban development. In times of constrained budgets city leaders carefully need to identify their infrastructure investments ensuring that their investments address their environmental and economic priorities. Technologies need to be adapted to serve local needs to ensure that the right technologies are applied in the right environments, tailored to the specific characteristics of the individual city (Fig. 1).

To tackle these questions, Siemens has developed an interactive and comprehensive tool-the City Performance Tool (CyPT) [2]. It gives guidance to a city on how to achieve their environmental targets while providing an indication on how each infrastructure-related decision will influence job creation and the infrastructure sector growth. The results of the CyPT approach for a city is shown in Fig. 2. The main categories depicted are $\mathrm{GhG}$ emission reductions in $\mathrm{MtCO}_{2}$ equivalents per year, air quality from $\mathrm{kt} \mathrm{NO}_{\mathrm{x}}$ and kt PM10 per year for time horizons from 2020 through 2050. The darker line represents the city target and the lighter line the reduction results calculated from the parameterized LCA model.

\section{The City Performance Tool-Methodology and Process}

The City Performance Tool is a dynamic simulation tool which studies a series of more than 70 technologies from Building, Transport and Energy Technologies - at different time periods and implementation rates. It covers greenhouse gas emissions from buildings and transport, as well as air pollutants such as particulate matter (PM) and nitrogen oxides $\left(\mathrm{NO}_{\mathrm{x}}\right)$. It also looks at the creation of new local jobs to install, operate and maintain city solutions. In transport, for example, CyPT assesses how a technology would reduce demand (reduce parking search traffic), shift the mode (public transport instead of cars) or improve efficiency (automated trains). The model is based on Life Cycle Assessment (LCA) methodology and builds upon Siemens' technology expertise and global databases of deep vertical 


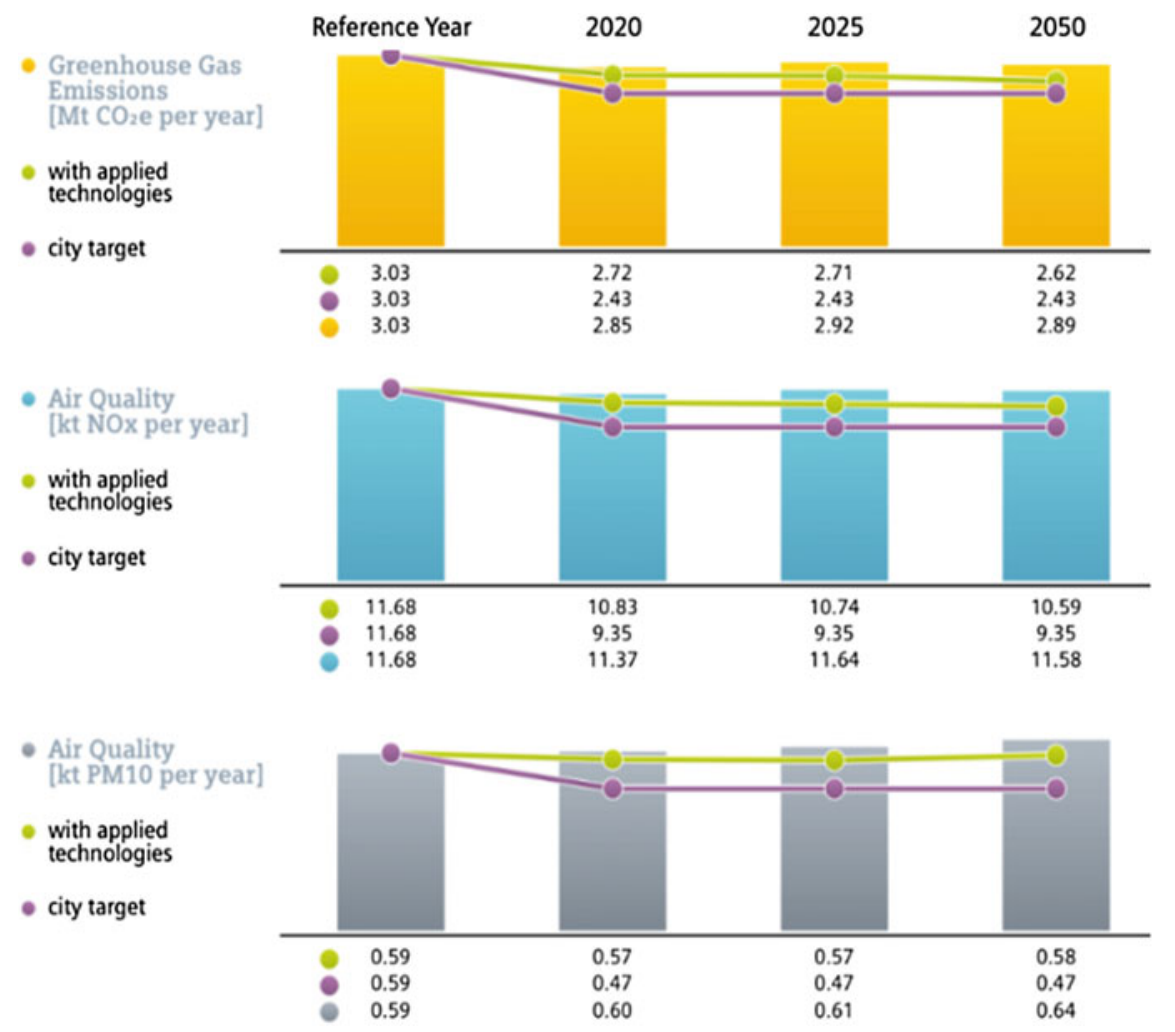

Fig. 2 Environmental reduction using CyPT methodology: results of applying a combination of different technology levers (light) are compared to City targets for the categories GhG-emissions and air quality

process knowledge. It can determine the implementation rate needed for your city to meet its future environmental targets. It can also measure the impacts of a city's strategic plans, and compare traditional methods with state-of-the-art technologies for their benefits and value for money.

The methods and tools are a combination of conventional LCA, consequential LCA, greenhouse gas accounting for cities and futurology. Even though the software and modelling concept such as the functional units are common LCA-based, the model is aligned with the GPC-Protocol [3]. Forecasting elements are included from HBEFA [4] for market and technology development.

In total 70 technology levers from energy system, buildings and transport are included in the LCA parameter model. Thus are 20 electricity generation and 20 heat generation technologies, 10+ building types with its electricity, heat and cooling demand, 10 freight modes; 35 passenger transport modes; 15 road and rail infrastructure elements. To establish a baseline, the model requires data to determine the level of maturity of the infrastructure system and its individual 
Table 1 Lever description of the 70 technology levers in buildings, transportation and energy

\begin{tabular}{|c|c|c|}
\hline Buildings & Transportation & Energy \\
\hline Wall insulation & Tram & Photovoltaic \\
\hline Glazing & Metro & $\begin{array}{l}\text { Wind power generation, } \\
\text { combined cycle gas } \\
\text { turbine }\end{array}$ \\
\hline Building envelop & $\begin{array}{l}\text { Regional train: new vehicles, new line, } \\
\text { reduced headway }\end{array}$ & Combined heat and power \\
\hline Efficient lighting & ATO Automated Train Operation & $\begin{array}{l}\text { Network optimization, } \\
\text { smart grid for monitoring } \\
\text { and automation }\end{array}$ \\
\hline $\begin{array}{l}\text { Demand oriented } \\
\text { lighting }\end{array}$ & Regenerative braking & $\begin{array}{l}\text { Power system automation } \\
\& \text { optimized network }\end{array}$ \\
\hline $\begin{array}{l}\text { Demand controlled } \\
\text { ventilation }\end{array}$ & Bus & Smart metering \\
\hline $\begin{array}{l}\text { Building efficiency } \\
\text { monitoring }\end{array}$ & $\begin{array}{l}\text { Car: CNG, hybrid, plug-in, electric, } \\
\text { hydrogen }\end{array}$ & $\begin{array}{l}\text { On shore power supply in } \\
\text { harbors }\end{array}$ \\
\hline $\begin{array}{l}\text { Efficient motors \& } \\
\text { drives }\end{array}$ & LED street lighting & \\
\hline Room automation & $\begin{array}{l}\text { Smart street lighting, intelligent traffic } \\
\text { light management }\end{array}$ & \\
\hline $\begin{array}{l}\text { HVAC \& } \\
\text { lighting + blinds }\end{array}$ & Intermodal traffic management & \\
\hline $\begin{array}{l}\text { Building automation, } \\
\text { BACS A,B,C, remote } \\
\text { monitoring }\end{array}$ & Low emission zone (truck) & \\
\hline Heat recovery & $\begin{array}{l}\text { Eco driving training, urban bike } \\
\text { sharing, cycling highway, occupancy } \\
\text { dependent } \mathrm{T} \text {, tolling, city tolling }\end{array}$ & \\
\hline \multirow{6}{*}{$\begin{array}{l}\text { Building performance } \\
\text { optimization }\end{array}$} & E-Ticketing & \\
\hline & E-Car sharing & \\
\hline & E-Highway & \\
\hline & e-BRT & \\
\hline & Freight ram & \\
\hline & Freight rail electrification & \\
\hline
\end{tabular}

components. This is necessary to later calculate the impact of levers. Levers are new technology or measures that are introduced to the system. The list of levers is depicted in Table 1.

The common CYPT model determines the variety of process blocks to build any city in a common LCA tool (SimaPro) [5]: in Fig. 3 the underlying LCA model is depicted for the building sector.

The baseline model is using city data publicly available mostly from statistics, studies, and transport or household surveys. Around 300 city-specific data points are used for three main sectors: electricity, heating, and cooling demand for 


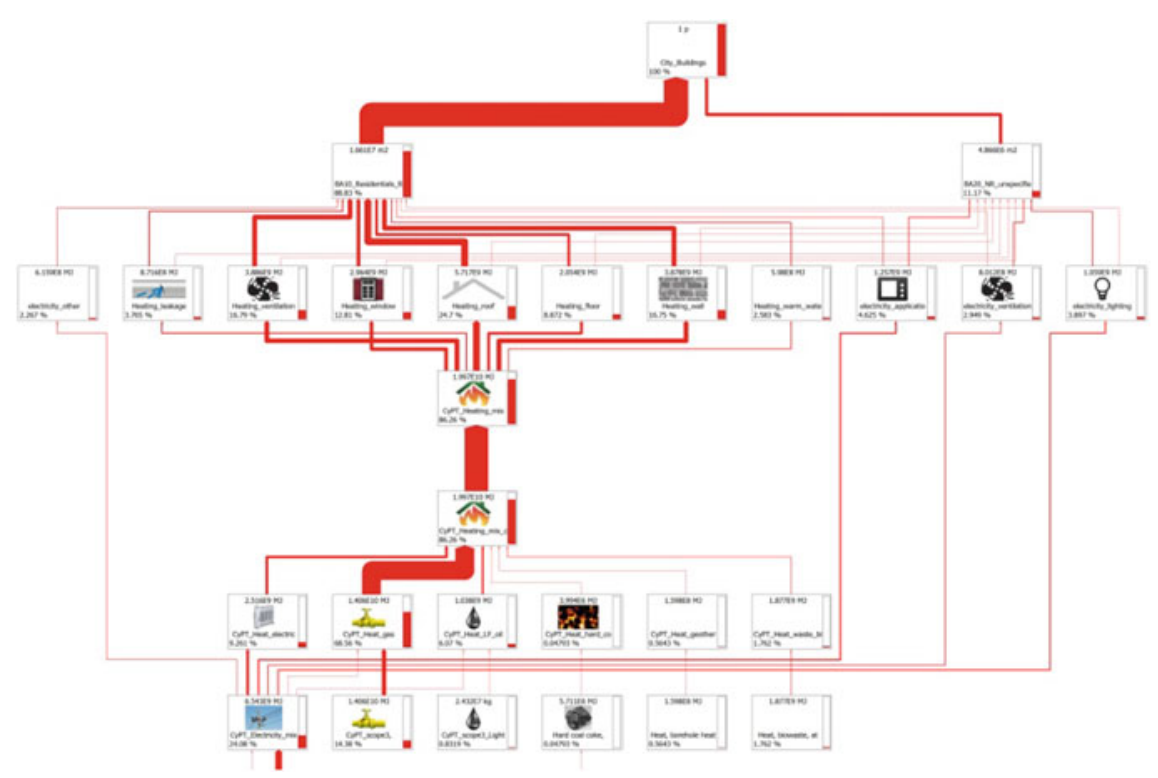

Fig. 3 Subset of lever model: each technology is parameterized by input emissions factors from the SimaPro model

buildings; passenger and freight transport demand; and the transport network. The model baseline of the of a City's lever network includes more than 2000 single processes, and more than 1000 customized parameters. This baseline has three KPIs - PM10 and $\mathrm{NO}_{\mathrm{x}}$ (air quality) and $\mathrm{CO}_{2}$ eq. emissions - which are also projected into the future based on a business-as-usual scenario and your own city's demand projection (if available). This calculation delivers a basic understanding of the root causes of emissions in your city's buildings and transport. A range of impacts can be studied based on a single lever and its implementation rates, comparing options, or combining several levers in one or more sectors [6].

Then mitigation strategies are applied in terms of what-if scenarios, by answering the following questions: Which and how much energy is required to serve the city's demand in transport and buildings? Which infrastructure technologies are available, what is the efficiency of, how can the demand shifted or reduced?

The calculation of the KPI's starts with the determination of demand which is than split into the contributing technologies. This is displayed in Fig. 3. Emissions related to buildings are a sum of heating, electricity etc. and its contributing technologies i.e. heat from gas. The CyPT model is multi-process LCA model, the change of one parameter defines a scenario, describing the transformation of the given infrastructure over time (Fig. 4).

Due to the scenario-based approach of the CyPT a process was developed to ensure the full stakeholder involvement of city representatives. At the beginning of 


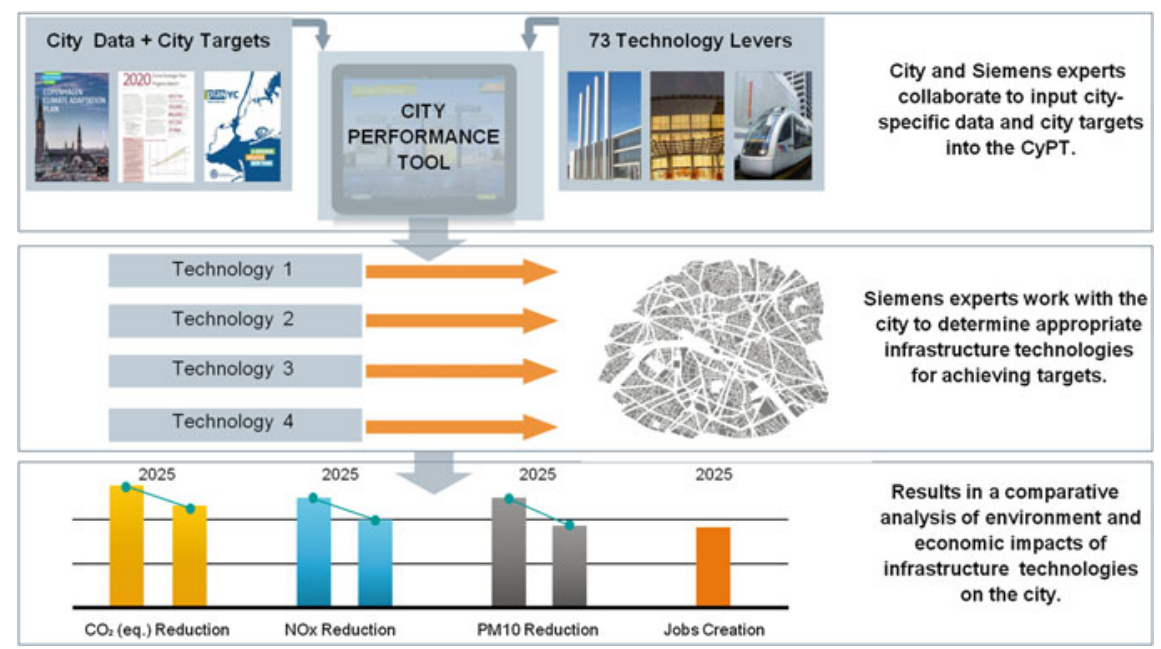

Fig. 4 Process of CyPT application in cities: collaboration starts in data collection using the LCAmodel and the impacts of technologies for KPI's like $\mathrm{CO}_{2}$ emission or air quality reduction

the process, data is collected on your city's energy, buildings and transport infrastructure to customize the CyPT model. Once all the data is collected, the CyPT Manager calculates the environmental baseline for your city based on activities in the three sectors. Comparing the results with your own targets it identifies future needs and improvement areas. The CyPT Manager also calculates the city-specific impacts of individual technologies. Levers can be pre-selected based on results, and city specific plans and policy can also be considered valuable mix of solutions.

A specially developed CyPT app visualizes the effects of individual levers on a city, its buildings and its transport system [7].

\section{Inside-Out View-Results from Vienna, Copenhagen and Minneapolis}

To understand the outside-in view we will present and discuss results of the CyPT projects and the resulting infrastructure reports from three different cities: Vienna [8], Copenhagen [9] and Minneapolis [10].

Vienna has set 2025 as the ambitious target year for the city to implement major infrastructure technologies in order to meet its environmental and economic targets. This study quantifies the benefits of over thirty building, energy and transport technologies and makes recommendations of which infrastructure solutions the city should be prioritizing in the run up to 2025, see Fig. 5. This study tested some of the technologies in Vienna's climate action programs named KLiP I and II. It was 


\begin{tabular}{|c|}
\hline $\begin{array}{l}\text { Vienna First } \\
\text { Technologies implemented }\end{array}$ \\
\hline Increased CHP contribution \\
\hline Residential wall insulation \\
\hline Residential doublentriple glazing \\
\hline Commercial wall insulation \\
\hline Commercial doubleftriple glazing \\
\hline LED street lighting \\
\hline Metro ATO \\
\hline CNG cars \\
\hline Hybrid electric vehicles \\
\hline Intermodal trafic management \\
\hline
\end{tabular}

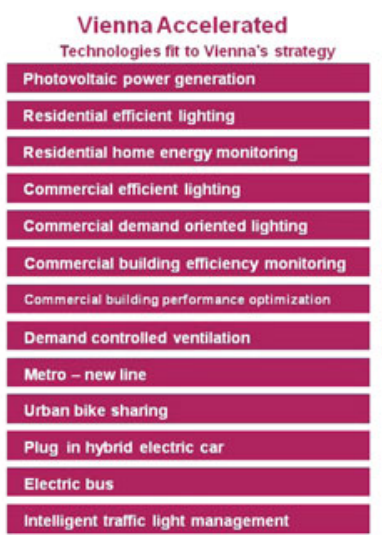

Vienna Experimental

Additional technologies to be implemented Residential home automation

Commercial heat recovery

Hybrid electric bus

Train - ATO

Electric cars

Electric taxis

Demand oriented street lighting

Electric car sharing

Fig. 5 Lever mix used in the Vienna CyPT project from already implemented to experimental technologies

found that solutions are cost effective in reducing $\mathrm{CO}_{2}$ eq. levels and improving air quality, the city will need to implement more of these intensive carbon reduction technologies if it is to meet its 2030 targets.

An investment of $€ 8$ bn over the next decade is needed to implement a set of technologies that can reduce $\mathrm{CO}_{2}$ eq. emissions in Vienna by $9 \mathrm{Mt}$ and add 85,000 full time equivalent jobs to the local economy. In this model, the city is currently achieving its reductions predominantly through building and energy technologies that are more expensive and do not improve air quality as effectively. Vienna has some untapped cost-effective technology opportunities to meet its $\mathrm{CO}_{2}$ mitigation targets. In the energy sector, the city should continue its implementation of combined heat and power (Fig. 6).

In the transport sector, the city should invest in new cutting-edge technologies such as intermodal traffic management applications, electric car and electric taxi solutions. These are win-win cost effective solutions that tackle $\mathrm{CO}_{2}$ emissions, improve air quality and increase local jobs.

Minneapolis and its development organization Xcel has set a "80 by 50" target, meaning $80 \%$ reduction of GhG emissions by 2050 [8]. The outcome of CyPT study shows that its utilities need to use $65 \%$ clean energy sources as a base of their energy mix (Fig. 7).

But even with this step, Xcel will have to continue greening its electricity by implementing 40 buildings and transportation technologies and adopted at their highest implementation rates by 2050 to ensure that targets are met. Our results show that, if the electricity mix gets significantly cleaner, the top performing technologies for reducing carbon emissions include (1) electrifying both passenger and freight road transport and (2) improving energy efficiency in buildings, particularly in commercial and government buildings. The technology mix and its resulting improvements in air quality are depicted in Fig. 8. Additional benefits could be realized from public transit, if more people could be attracted to use it. 

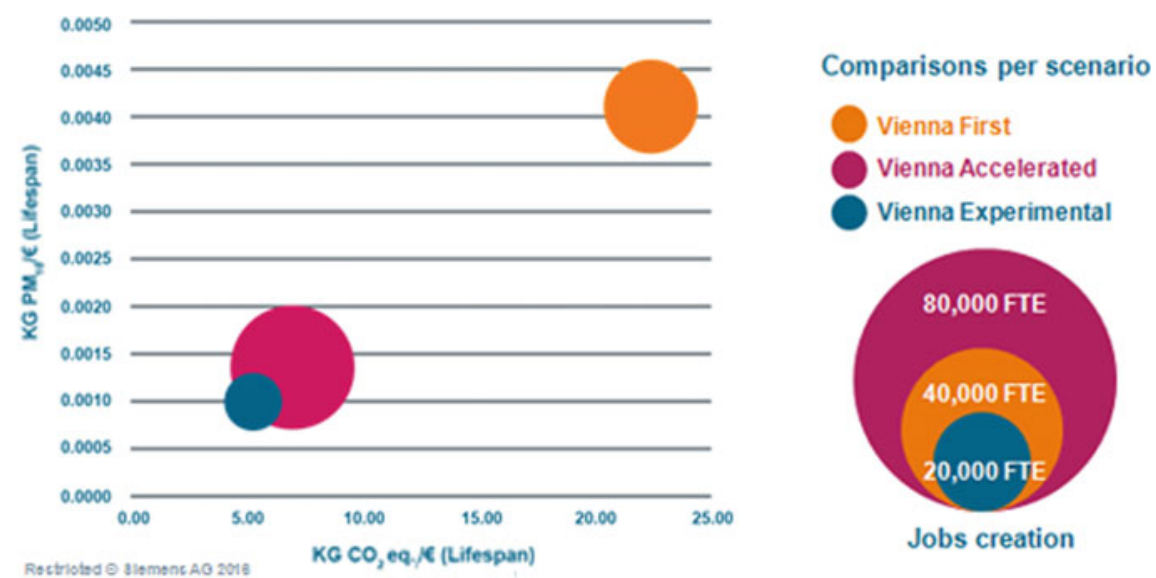

Fig. 6 Cost effectiveness comparison: the larger the bubble the more jobs the technology will induce. Bubbles on the top right of the chart, reduce the larger amount of greenhouse gases and PM10 levels per unit of investment Technologies such as plug-in hybrid electric cars that improve air quality and reduce $\mathrm{CO}_{2}$ most effectively

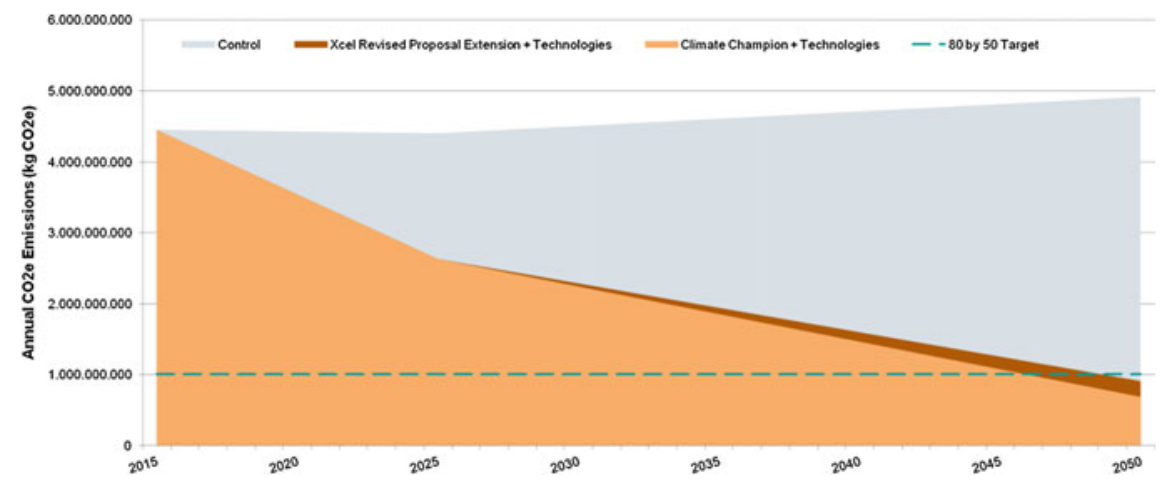

Fig. 7 Resulting emission reduction $\left(\mathrm{CO}_{2}\right.$ eq.) applying a $65 \%$ clean energy mix

Copenhagen has been and continues to lead cities on climate policy globally. It ranked top of Siemens' European Green City Index in 2009 [11], and it is making great strides meeting its 2025 target for carbon neutrality. Siemens has used the CyPT and found that the City of Copenhagen is reducing emissions from nearly all of the sources where it has significant control in energy and transport.

Copenhagen is decoupling its $\mathrm{CO}_{2}$ eq. emissions so that despite a growing population and increasing building floor-space, carbon emissions are expected to decrease over the next 10 years. This is predominantly derived from greener national electricity and local heating mixes. Using our accounting standard that captures direct and indirect emissions, our model quantifies these savings as high as 


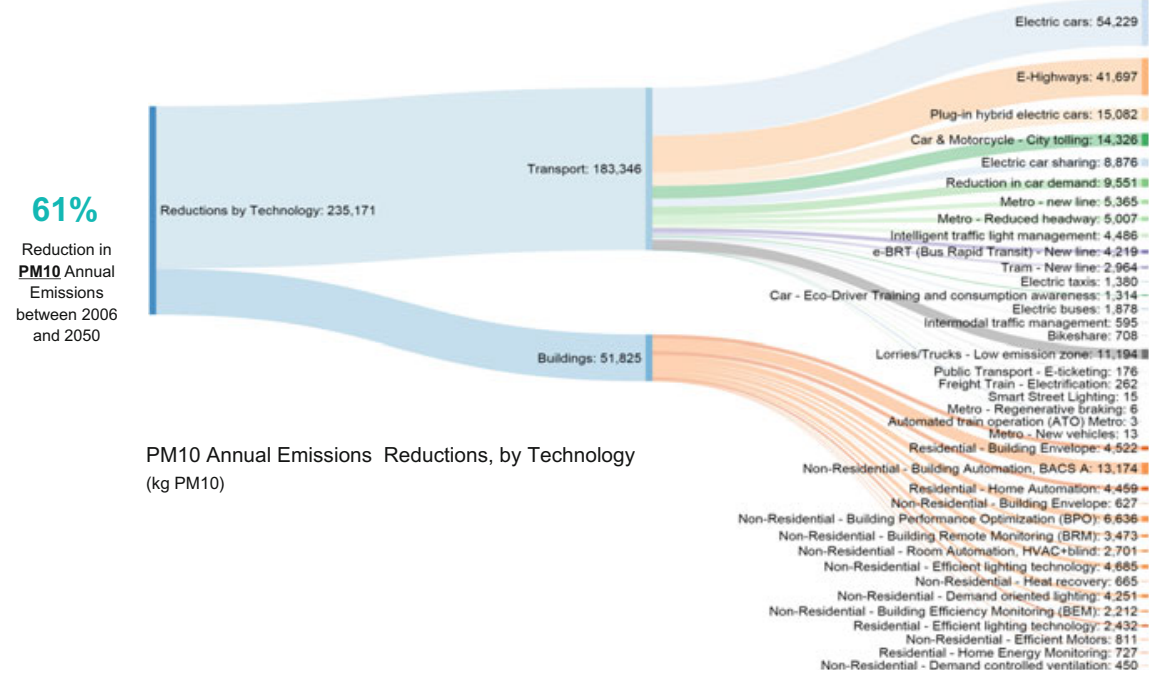

Fig. 8 The CyPT for Minneapolis shows which technology has the greatest air quality improvement potential and its reduction values

$12 \%$ of current annual emissions. These are savings achieved from the expansion of wind power and biomass for combined heat and power in the 2025 Climate Plan. Maintaining its global leadership position will require delivering further building upgrades within its own public stock and incentivizing private building owners to take action to improve the efficiency of their buildings. The city will also have to stimulate a market shift towards cleaner vehicles and a modal shift towards low carbon public transportation. The report indicates that intelligent administrative inner-city infrastructure investments in energy or mass transit must be accompanied by effective incentives for the private sector, as well as a good national framework to promote alternative mobility and cost-effective renewable energy (Fig. 9).

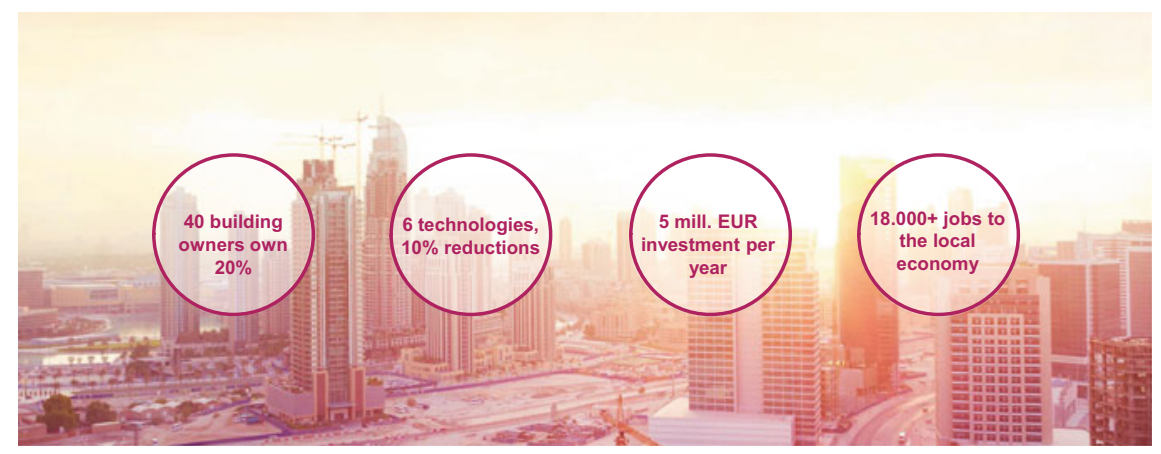

Fig. 9 Major CyPT results for Copenhagen 


\begin{tabular}{|l|l|l|l|}
\hline Lever & \% Reductions CO.e & $\mathrm{kg}$ CO, eq savings / CAPEX & Total jobs \\
\hline Bullding Effiliclency Monitoring (BEM) & $0.7 \%$ & 1.3 & 900 \\
\hline Bullding Performance Optimization (BPO) & $2 \%$ & 5 & 400 \\
\hline Heat recovery & $1.3 \%$ & 0.1 & 2,600 \\
\hline Bullding Automation, BACS A & $4 \%$ & 0.1 & 5,400 \\
\hline Room Automation, HVAC+bllind & $1 \%$ & 0 & 8,000 \\
\hline Bullding Remote Monitoring (BRM) & $1 \%$ & 2 & 1,400 \\
\hline
\end{tabular}

Fig. 10 Shortlisted smart technologies providing the largest savings

For example, buildings are responsible for around $80 \%$ of Copenhagen's greenhouse emissions - and almost a third of the commercial building stock is managed by just 40 owners. If these owners have an incentive to invest in six cutting-edge building technologies selected by the CyPT, the city could save $10 \%$ of its emissions and create more 18,000 jobs over the next 10 years.

As buildings become more sustainable, transportation begins to have a bigger contribution to emissions. The report shows that, by 2050, transportation will account for $27 \%$ of Copenhagen's emissions, as opposed to $20 \%$ today. The big surprise in the Siemens "Copenhagen's Big Incentive" report is that the most effective technology investments are outside of the city's budgeting program.

It is about "national investments in wind, private investments in building retrofitting, and household and business investment in alternative cars." In figures: $95 \%$ of the estimated three billion euros needed to save an additional $26 \%$ of city-wide emissions over the next 10 years are outside of the city budget. This indicates the investment strategy of Copenhagen must be aligned to the state or governmental plans (Fig. 10).

\section{Conclusions}

Modern cities constantly need to balance long-term targets such as reducing greenhouse gas emissions with shorter term aims such as improving air quality and creating jobs. All too often, lack of public support means long-term objectives are sacrificed for more immediate needs. The cities in the world have different focuses on environmental, economic or social aspects/KPIs. These differ by region, in scope (Carbon Accounting Scope 1-3), in time (in terms of target setting, short term for air pollutants, long term for GHG-emissions) and at last by infrastructure vertical. The LCA based decision support approach CyPT is presented in this paper. A parameterized LCA model is used to calculate the $\mathrm{GhG}$ and air quality emissions from 70 technologies applied in cities. CyPT takes on the challenges of this balancing act by helping decision makers to recognise and select technologies that offer win-win solutions. This is shown in the example of Minneapolis and the air 
quality improvement potentials and the underlying technology mix. CyPT highlights the benefits from key performance indicators to enable city leaders to deliver long-term advantages strongly linked to short-term gains. Cities can maximise CyPT results by identifying the most cost-effective solutions for improving air quality and reducing greenhouse gas emissions. By studying capital and operational investments across the lifespan of each technology, CyPT can report on kilograms of $\mathrm{CO}_{2}$ eq. as well as PM10 and $\mathrm{NO}_{\mathrm{x}}$ levels for every euro spent. This was shown in the example of Vienna, where untapped cost-effective technology opportunities show how to meet its $\mathrm{CO}_{2}$ mitigation targets. The CyPT helps to optimize investment strategies for your city's long-term needs. This was shown at the example of Copenhagen, where almost all of the technology investments must come from sources outside of the city budget.

\section{References}

1. Economist.com (2014),. Investing in infrastructure: The trillion dollar ga. Available at: http:// www.economist.com/news/leaders/21599358-how-get-more-wolrds-savings-pay-new-roadsairports-and-electricity.

2. https://www.siemens.com/global/en/home/company/topic-areas/intelligent-infrastructure/ cities-on-the-move.html??stc=wwcg 106121 .

3. Fong W, Sotos M, Doust M, et al., The Global Protocol for Community-Scale Greenhouse Gas Emission Inventories (GPC), 1st Ed., Greensouse Gas Protocol, 2014. http://ghgprotocol. org/greenhouse-gas-protocol-accounting-reporting-standard-cities, (Accessed 18.04.2017).

4. Keller M, Wuethrich P, Ickert L, Schmied M, Stutzer B, et al., Handbook Emission Factors for Road Transport, 3.2 Ed., INFRAS AG, 25.7.2014.

5. https://simapro.com/licences/\#/business.

6. https://www.siemens.com/de/de/home/unternehmen/themenfelder/intelligente-infrastruktur/ city-performance-tool.html.

7. http://www.dgterritorio.pt/2015-4-23-10-20-42-78__SavvasVerdisUrbanAnalyticsLisbon 2015. pdf.

8. https://www.siemens.com/content/dam/internet/siemens-com/global/company/topic-areas/ intelligent-infrastructuree/resilience/report/summary-vienna-report-oct-2014.pdf.

9. https://www.siemens.com/content/dam/internet/siemens-com/global/company/topic-areas/ intelligent-infrastructuree/resilience/report/summary-copenhagen-cypt-report-oct-2015.pdf.

10. https://www.siemens.com/content/dam/internet/siemens-com/global/company/topic-areas/ intelligent-infrastructuree/resilience/report/summary-minneapolis-cypt-report-dec-2015.pdf.

11. http://www.siemens.com/entry/cc/features/greencityindex_international/all/de/pdf/gci_report_ summary.pdf. 
Open Access This chapter is licensed under the terms of the Creative Commons Attribution 4.0 International License (http://creativecommons.org/licenses/by/4.0/), which permits use, sharing, adaptation, distribution and reproduction in any medium or format, as long as you give appropriate credit to the original author(s) and the source, provide a link to the Creative Commons license and indicate if changes were made.

The images or other third party material in this chapter are included in the chapter's Creative Commons license, unless indicated otherwise in a credit line to the material. If material is not included in the chapter's Creative Commons license and your intended use is not permitted by statutory regulation or exceeds the permitted use, you will need to obtain permission directly from the copyright holder.

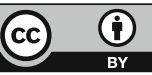

